AUTORES:

Israel Hidenburgo Aniceto Cintra $^{1}$

Maria Cristina Alves Maneschy ${ }^{2}$

Anastácio Afonso Juras ${ }^{3}$

Rafaella do Socorro Nunes Mourão ${ }^{4}$

Masayoshi Ogawa

${ }^{1}$ Ufra, 66.077-530, Belém, PA, Brasil.

2 UFPA, 66.075-900, Belém, PA, Brasil.

${ }^{3}$ Eletronorte, 77.018-990, Brasileira, DF, Brasil.

${ }^{4}$ Intituto Chico Mendes de Conservação da Biodiversidade, Centro de Pesquisa e Gestão de Recursos Pesqueiros do Litoral Norte, 66.077-530, Belém, PA, Brasil.

${ }^{5}$ UFC, 60.356-000, Fortaleza,

CE, Brasil.

Recebido: 15/02/2011

Aprovado: 11/05/2011

AUTOR CORRESPONDENTE:

Israel Hidenburgo Aniceto Cintra

E-mail: israelcintra@terra.com.br

PALAVRAS-CHAVE:

Águas públicas

Caracterização sociodemográfica

Percepção ambiental

Pesca

KEY WORDS:

Environmental perception

Fisheries

Public waters

Social and demographic

characterization
Revista de Cièncias Agrärias

AMAZGNIAN JOURNAL

of Agricultural and Environmental Sciences

www.ajaes.ufra.edu.br

\section{Pescadores artesanais do reservatório da usina hidrelétrica de Tucuruí (Pará, Brasil)}

\author{
Artisanal fishermen from the reservoir of the Tucuruî \\ hydroelectric power station, in the Brazilian State \\ of Pará
}

Resumo: Neste estudo busca-se caracterizar os pescadores que atuam na pesca artesanal no reservatório de Tucuruí e levantar suas percepções acerca do estado dos recursos pesqueiros na área. Os dados foram coletados nos meses de junho, agosto e setembro de 2006, nos municípios de integração do reservatório. É dada ênfase ao local de nascimento, estado civil, número de dependentes, estrutura etária, escolaridade, tempo de atividade, profissão anterior e às causas da redução da produção de peixes. Constatou-se: forte proporção de migrantes (45\%); destes, a maioria proveniente do Nordeste brasileiro, com destaque para o Estado do Maranhão, que representava $27 \%$ do total de pescadores; as pescarias eram principalmente praticadas por homens $(68 \%)$, que viviam maritalmente (74\%), com idade média de 37 anos e com 3 a 4 filhos em média; o nível de escolaridade era baixo e $41 \%$ dos pescadores nunca haviam exercido outra atividade além da pesca. Quanto ao tempo de atuação na pesca, um grupo atuava há mais de 20 anos (28\%) e outro, majoritário, há menos de 19 anos (72\%). Contudo, as percepções correntes entre os entrevistados eram de que os estoques de peixes de interesse comercial estavam em declínio, o que justifica a realização de estudos para subsidiar sua gestão.

Abstract: This study seeks to characterize the fishermen who work in artisanal fisheries in the reservoir formed by the damming of the Tocantins River to form the Tucuruí Hydroelectric Power Station. Data were collected during June, August and September of 2006. Emphasis is given to the place of birth, marital status, number of dependents, age, education, length of service, previous career and causes of the reduction in production. The interviews with the fishermen led to the following conclusions: most of the fishermen are from the State of Pará (55\%); $42 \%$ of the immigrants come from the Northeast region, especially the State of Maranhão which was the place of origin of $27 \%$ of the fishermen interviewed; the fisheries are run by men (68\%), living with a partner $(74 \%)$, the average age is 37 years and they have an average of 3 to 4 children; the level of education is very low and $41 \%$ of the fishermen have never had any other kind of occupation. There are 2 groups of fishermen, a group that has worked in the fishing industry for more than 20 years (28\%) and another that has worked for 19 years or less in the industry (72\%). However, current perceptions among respondents were that the stocks of commercial interest were declining, which justifies the need for future studies to provide support for management of these. 


\section{Introdução}

Desde o início das civilizações, a pesca representa um meio para a sobrevivência de uma grande parcela da população mundial, não devendo ser subestimada na produção de alimentos para as populações atuais e futuras (COS'TA, 2003).

A exploração de recursos naturais renováveis remonta ao período anterior à colonização e sempre se destacou como uma das atividades tradicionais para as populações da Amazônia (GOULDING, 1983).

A instalação de usinas hidrelétricas está sempre relacionada a uma série de impactos ambientais, em especial para a fauna de peixes que habitam os cursos d'água represados (AGOSTINHO; GOMES; PELICICE, 2007), sem falar nos impactos sociais, com populações deslocadas e que têm suas fontes de sobrevivência fortemente alteradas. Porém, no caso da UHE Tucuruí, apesar dos muitos impactos originados pelo represamento em 'Tucuruí, uma importante fonte de subsistência e de geração de renda para a população ribeirinha do reservatório permaneceu: a pesca artesanal (CAMARGO; PETRERE-JÚNIOR, 2004).

Agostinho, Gomes e Pelicice (2007) relatam que, em 1986, a pesca se instalou no reservatório de Tucuruí de maneira espontânea, dois anos após a sua construção. Os mesmos autores registraram a presença de dois tipos de pescaria no reservatório: a profissional (comercial) e a esportiva, sendo que esta última ocorria de forma esporádica. Almeida et al. (2006) afirmam que a pesca comercial e a de subsistência são fundamentais para a economia regional da Amazônia. Assim, o pescado se tornou a principal fonte de renda e de proteína na região, sendo que a pesca nos reservatórios se tornou uma peça chave no abastecimento dos mercados urbanos próximos, aprovisionando também outras regiões.

Dada a importância do reservatório da Usina Hidrelétrica de Tucuruí (UHE Tucuruí) no contexto pesqueiro nacional, é necessário conhecer o perfil sociodemográfico dos pescadores e suas origens, avaliar se existe redução da produção e quais suas possíveis causas.

Este estudo volta-se a essa temática e pretende fornecer subsídios para o desenvolvimento da atividade pesqueira, manejo dos estoques pesqueiros e melhoria da condição econômica das populações que dependem direta ou indiretamente da pesca local.

Assim, o objetivo deste trabalho foi caracterizar os pescadores que atuam na pesca artesanal no reservatório de Túcuruí e levantar suas percepções acerca do estado dos recursos pesqueiros na área.

\section{Material e Métodos}

A Usina Hidrelétrica de Tùcuruí está localizada no canal principal do rio Tocantins, no Estado do Pará, a 7,5 km a montante do município de Tucuruí e a $300 \mathrm{~km}$ em linha reta da cidade de Belém (CMB, 1999). O reservatório é a zona de inundação, que chega até um pouco antes da cidade de Itupiranga, situada a $170 \mathrm{~km}$ da barragem da UHE de Tucuruí e compreende os municípios de Nova Ipixuna, Jacundá, Novo Repartimento, Goianésia do Pará, Breu Branco e Tucuruí (JURAS; CINTRA; LUDOVINO, 2004) (Figura 1).

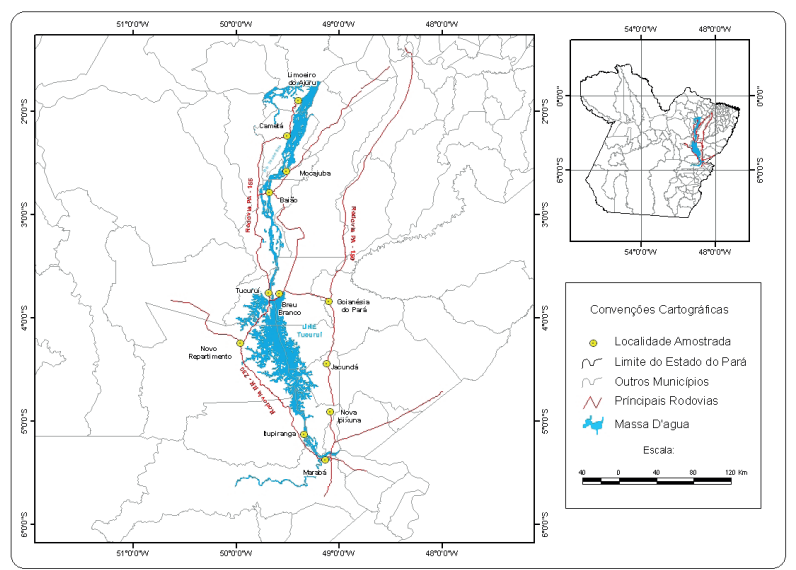

Figura 1. Mapa de localização do reservatório de Tưcuruí, destacando os municípios sob influência da Usina Hidrelétrica de Tùcuruí.

Os dados foram coletados nos meses de junho, agosto e setembro de 2006, nos municípios de integração do reservatório da UHE de Tùcuruí (Nova Ipixuna, Jacundá, Novo Repartimento, Goianésia do Pará, Breu Branco e Tucuruí). Para a definição da amostra de entrevistados, foi adotado o "Método de Amostragem de Conveniência", preconizado por Anderson, Sweeney e Williams (2002), que tem a vantagem de tornar relativamente fácil a seleção da amostra e a coleta dos dados, quando não é possível dispor de dados sobre o tamanho da população investigada; porém, este método não permite fazer extrapolação, restringindo a análise para o tamanho da amostra analisada.

Dada a impossibilidade de proceder a uma amostra aleatória, a qual produziria maior precisão estatística, estabeleceu-se o tamanho da amostra considerando a indicação de estatísticos de que, 
para este tipo de estudo, uma amostra de 30 entrevistados por localidade seria suficiente. Segundo os mesmos, este número possibilitaria uma significância no cálculo das médias para cada amostra. Assim, definiu-se como meta entrevistar todos os pescadores disponíveis em cada porto, de maneira aleatória, até atingir o objetivo. Caso em três dias não fosse possível atingir o número desejado (30 entrevistas), a amostragem seria considerada satisfatória, já que ela seria posteriormente analisada em conjunto com as demais localidades do reservatório da UHE de Tùcuruí.

As entrevistas e questionários semiestruturados foram aplicados aos pescadores, nos portos de desembarque e/ou em suas residências.

Procurou-se traçar o perfil sociodemográfico dos pescadores, incluindo local de nascimento, estado civil, estrutura etária, nível de instrução, tempo na atividade, profissão anterior e número de dependentes; igualmente, a avaliação do entrevistado quanto à redução ou aumento da produção de pescado no reservatório e suas possíveis causas.

Para estimar o número de dependentes por pescador seguiu-se o conceito de família adotado pela Secretaria Executiva de Trabalho e Promoção Social - Seteps (2003), como sendo "o conjunto de pessoas ligadas por laços de parentesco, dependência doméstica ou normas de convivência, que resida na mesma unidade domiciliar e, também, a pessoa que more só em uma unidade domiciliar".

As informações apresentadas a seguir são resultantes dos questionários aplicados nos seis municípios do reservatório da UHE Tucuruí. Levam em conta a distribuição de frequência de respostas para cada questão. Durante as viagens, observações e registros fotográficos foram realizados. A consulta à bibliografia disponível possibilitou complementar as informações obtidas em campo. Para a obtenção dos valores gerais, os dados foram agrupados em um banco de dados do programa Excel para análise e apresentação gráfica.

\section{Resultados e Discussão}

No estudo, foram entrevistados 142 pescadores: Nova Ipixuna ( $\mathrm{n}=13)$, Jacundá ( $\mathrm{n}=28)$, Novo Repartimento ( $\mathrm{n}=29)$, Goianésia do Pará $(\mathrm{n}=12)$, Breu Branco $(\mathrm{n}=30)$ e Tucuruí $(\mathrm{n}=30)$, totalizando 142 questionários preenchidos.

A maior parcela dos pescadores em atividade no reservatório da Usina Hidrelétrica de Tucuruí era paraense $(55 \%)$ e os demais $45 \%$ tinham vindo de outros estados, o que indica uma proporção muito expressiva de migrantes. O Nordeste representava $42 \%$ dentre as regióes de origem e o maior destaque foi atribuído ao Estado do Maranhão, que representava $27 \%$ do total de pescadores (Figura 2). A grande proporção de nordestinos pode ser atribuída às poucas oportunidades de trabalho em seus meios de origem e à atração que a instalação de grandes projetos naquela porção do território amazônico exercia, vistos como oportunidades de emprego e renda, não apenas no município de Tùcuruí, como nos demais em torno do reservatório e mais ao sul do Pará. A abertura de estradas, implantação de empreendimentos minerais e agropecuários, além da própria construção da hidrelétrica durante os anos 70 foram importantes fatores de atração populacional. Tal como ocorrera em outros períodos históricos (ciclo da borracha), a Amazônia continuava a receber migrantes nordestinos em busca de meios de sobrevivência. Segundo constatou Maneschy (1995), ao realizar um estudo em Bragança, no litoral paraense, parte desses migrantes ingressavam na pesca, fato esse corroborado neste estudo.

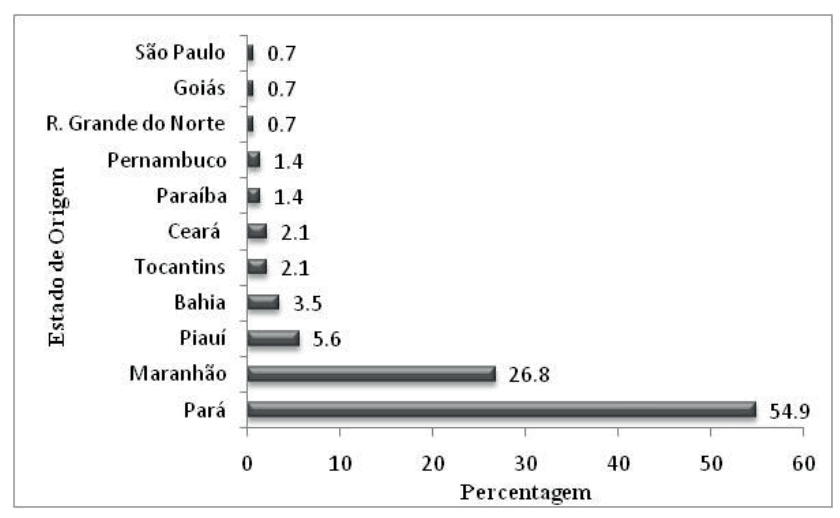

Figura 2. Principais estados de nascimento dos pescadores do reservatório da UHE Tùcuruí, no ano de 2006.

A Seteps (2003), ao investigar o local de nascimento dos pescadores artesanais do Pará, observou que $87,1 \%$ eram naturais do próprio Estado. Vale dizer que esse número incluía as regiões de menor dinamismo econômico e, portanto, que não apresentaram crescimento demográfico decorrente de imigração. Naquele estudo, os migrantes de outros estados também provinham em grande parte do Maranhão, com $37 \%$ dos entrevistados nessa condição.

Vale notar que o reservatório de Billings (São Paulo-SP) apresenta uma situação bem parecida com a do reservatório da UHE Tucuruí, pois, segundo Minte-Vera (1997), 56\% dos pescadores eram 
naturais do Estado de São Paulo e os demais, 44\%, originários de outros Estados, e, destes, apenas 28\% eram nordestinos. Brasil e Teixeira (2007) destacam que, dentre os estados do Nordeste que surgem como locais de origem dos migrantes no Estado do Amazonas, destacam-se Ceará, Maranhão, Bahia e Pernambuco.

Com relação aos pescadores naturais do Pará, observou-se um maior destaque em Cametá (27\%, $\mathrm{n}=21)$, município a jusante da barragem, Tucuruí $(17 \%, \mathrm{n}=13)$, Jacundá $(6,4 \%, \mathrm{n}=5)$, Marabá $(6,4 \%, n=5)$ e Mocajuba $(6,4 \%, n=5)$, este último também a jusante. Itupiranga $(3,85 \%, \mathrm{n}=3)$, Breu Branco $(1,28 \%, n=1)$, Nova Ipixuna $(1,28 \%$, $\mathrm{n}=1)$, Novo Repartimento $(3,85 \%, \mathrm{n}=3)$ e Baião $(3,85 \%, n=3)$ representaram, juntos, $14,10 \%$. Todos são considerados parte da área de influência da UHE Tucuruí. Assim, se observou que aproximadamente $77 \%$ dos pescadores naturais do Pará são originários dos municípios da área de influência da UHE de Túcuruí.

Além dos pescadores dos municípios da área de influência da UHE Tucuruí, observou-se uma migração de pescadores de municípios situados às margens dos rios Tocantins e Araguaia, possivelmente atraídos pela concentração de peixes do reservatório e pela carência de peixes a jusante, nos primeiros anos de formação do lago.

Nas últimas décadas, a Região Norte tem sido palco de grandes mudanças na sua dinâmica demográfica, impulsionadas pelas políticas governamentais no início da segunda metade do século passado. Nesse processo, novas tendências demográficas passaram a se delinear na região, com forte influência dos fluxos migratórios originários de outras regiões do país (inter-regionais), como também de dentro da própria região (intrarregionais), que resultaram em crescimento acelerado de sua população e em urbanização expressiva (BRASIL; TEIXEIRA, 2007). Os dados relativos à população de pescadores na área do reservatório de Tucuruí são um exemplo dessa dinâmica demográfica na região.

No reservatório, $74 \%$ dos pescadores entrevistados viviam maritalmente (legalmente casado, $41 \%,+$ união estável, 33\%), enquanto $21 \%$ eram solteiros, $4 \%$ foram casados e/ou estavam separados/divorciados e $1 \%$ constituído de pescadores viúvos.

Dos municípios localizados no reservatório, Nova Ipixuna foi o que apresentou a maior quantidade de pescadores solteiros (38\%), enquanto os de Tưcuruí (83\%) e Jacundá (82\%) apresentaram os maiores percentuais de pescadores vivendo maritalmente.

Esses dados diferem dos apresentados pela Seteps (2003), no que se refere aos pescadores entrevistados na condição de casados $(85,2 \%)$ e solteiros $(9,4 \%)$, e são semelhantes no tocante aos separados $(3,8 \%)$ e viúvos $(1,5 \%)$. Silva, Oliveira e Nunes (2007) observaram que, em Conceição do Araguaia (Pará), $71 \%$ dos pescadores eram casados, percentuais próximos aos encontrados para o reservatório da UHE Tùcuruí.

Ceregato e Petrere Júnior (2002) verificaram, no reservatório do Complexo Urubupungá, formado pelas Usinas Hidrelétricas de Jupiá e Ilha Solteira, no Estado de São Paulo, que 78\% dos pescadores eram casados, $16,5 \%$ solteiros, $4,3 \%$ separados/ divorciados e 1,2\% viúvos, dados próximos aos encontrados neste estudo.

Observou-se que $87 \%$ dos pescadores afirmaram ter filhos e esse número variou de 1 a 14 , com média estimada de 3 a 4 filhos por pescador. $\mathrm{O}$ município que apresentou a menor média foi Nova Ipixuna, com 2 a 3 filhos/pescador, e o de maior média foi Goianésia do Pará, com 4 a 5 filhos/pescador (Tabela 1).

Tabela 1. Número de pescadores com filhos e média de filhos/pescador por município localizado no reservatório da UHE de Tùcuruí, no ano de 2006.

\begin{tabular}{lccccccc}
\hline \multirow{2}{*}{ Município } & $\begin{array}{c}\text { Pescador s/ } \\
\text { filhos }\end{array}$ & $\begin{array}{c}\text { Pescador c/ } \\
\text { filhos }\end{array}$ & $\begin{array}{c}\text { Número de } \\
\text { filhos }\end{array}$ & Média \\
\cline { 2 - 8 } & $(\mathbf{n})$ & $\mathbf{( \% )}$ & $\mathbf{( n )}$ & $\mathbf{( \% )}$ & Mínimo & Máximo & $\begin{array}{c}\text { Filhos/ } \\
\text { Pescador }\end{array}$ \\
\hline Nova Ipixuma & 3 & 23 & 10 & 77 & 1 & 6 & 2.80 \\
Jacundá & 2 & 7 & 26 & 93 & 1 & 9 & 4.00 \\
Novo Repartimento & 8 & 28 & 21 & 72 & 1 & 10 & 3.95 \\
Goianésia do Pará & 5 & 42 & 7 & 58 & 1 & 6 & 4.43 \\
Breu Branco & 0 & 0 & 30 & 100 & 1 & 13 & 3.53 \\
Tucuruí & 1 & 3 & 29 & 97 & 1 & 14 & 4.17 \\
Reservatório & 19 & 13 & 123 & 87 & 1 & 14 & 3.85 \\
\hline
\end{tabular}

O percentual de pescadores sem descendentes correspondeu a $13,4 \%$ do total. Porém, a maior parte dos pescadores tinha de 1 a 4 filhos $(57,8 \%)$. Famílias mais numerosas, acima de 5 filhos, representaram 28,9\% (Figura 3).

O número médio de filhos entre as famílias dos pescadores entrevistados do reservatório da UHE Tucuruí é considerado alto, quando comparado com a média nacional que, em 2007, foi de 1,95 filhos por mulher. Segundo o IBGE (2008), tal valor traduz o resultado de um processo intenso e acelerado 
de declínio da fecundidade ocorrido na sociedade brasileira nas últimas décadas. Diversos países, especialmente os europeus, já atingiram valores bem abaixo do chamado nível de reposição natural da população, como a Itália, cuja taxa é de 1,38 filhos, contrastando com a Índia, com 2,81 filhos por mulher. Uma maneira de justificar a taxa alta de fecundidade na UHE Túcuruí, segundo os entrevistados, é que grande parte dos pescadores tinha filhos com mais de uma mulher, além do acesso restrito a métodos diferenciados de contracepção, o que inclui também falta de conhecimento sobre o tema e precariedade no atendimento público.

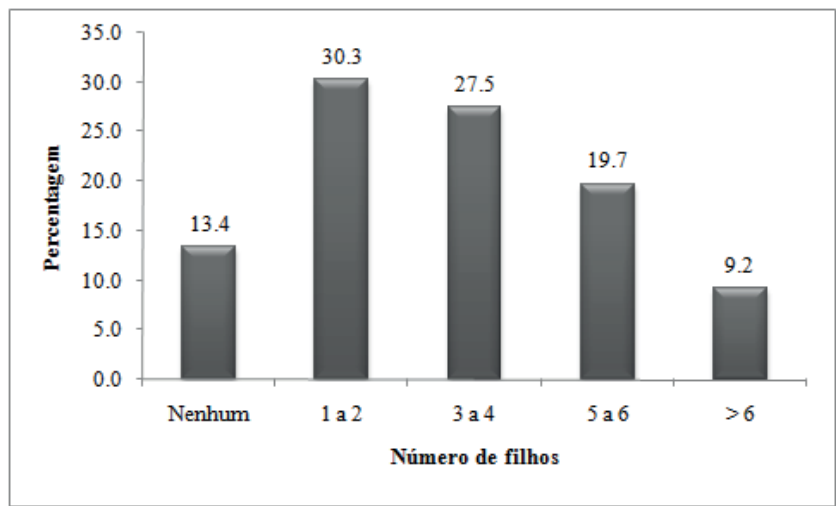

Figura 3. Frequência do número de filhos por pescador no reservatório da UHE de Tucuruí, no ano de 2006.

Quanto aos dependentes, encontrou-se uma média de 5,3 dependentes por pescador para o reservatório da UHE de Túcuruí. No mínimo, o pescador do reservatório de Tucuruí possuía 1 dependente e, no máximo, 14 (Tabela 2). A Seteps (2003) encontrou, para o Sudeste Paraense, ou seja, para a área objeto deste estudo, um número médio de 5,5 dependentes/pescador e, para o Pará, 6,0 dependentes/pescador. Importa destacar que o alto número de filhos e de dependentes entre os pescadores de Tucuruí revela o grande contingente populacional que depende diretamente da atividade pesqueira.

Do total de entrevistados, a grande maioria $(93 \%, \mathrm{n}=132)$ era de pessoas do sexo masculino, e $74 \%$ situavam-se em idades superiores a 30 anos, sendo a faixa etária dominante a de 40 a 49 anos, com 29\% dos pescadores. Dentre os maiores de 50 anos, $17 \%$ ainda se mantinham como pescadores, supondo-se que há duas justificativas para o percentual encontrado: as opções de emprego fora da pesca não absorviam trabalhador nesta faixa de idade; e os que ocupavam essa faixa estavam aposentados ou próximos da aposentadoria. É importante salientar que os pescadores são aposentados aos 55 e 60 anos, mulheres e homens, respectivamente. Apenas uma pequena parcela, menos de $8 \%$, tinha idade inferior a 20 anos, o que demonstra que a atividade era proporcionalmente pouco explorada pelos mais jovens que, de modo geral, vêm buscando a inserção em outras atividades, nos centros urbanos (Figura 4).

Tabela 2. Número de dependentes por pescador nos municípios e no reservatório da UHE de Tùcuruí, no ano de 2006.

\begin{tabular}{|c|c|c|c|c|c|}
\hline \multirow{2}{*}{ Município } & \multicolumn{2}{|c|}{ Número } & \multicolumn{2}{|c|}{$\begin{array}{l}\text { Número de } \\
\text { Dependentes }\end{array}$} & \multirow{2}{*}{$\begin{array}{c}\text { Média } \\
\begin{array}{c}\text { Dependente/ } \\
\text { Pescador }\end{array}\end{array}$} \\
\hline & Pescador & Dependentes & Mínimo & Máximo & \\
\hline Nova Ipixuma & 10 & 39 & 1 & 7 & 3.9 \\
\hline Jacundá & 16 & 91 & 3 & 14 & 5.7 \\
\hline Novo Repartimento & 19 & 100 & 1 & 10 & 5.3 \\
\hline Goianésia do Pará & 8 & 36 & 1 & 7 & 4.5 \\
\hline Breu Branco & 24 & 125 & 1 & 14 & 5.2 \\
\hline Tucuruí & 27 & 162 & 2 & 12 & 6.0 \\
\hline Total & 104 & 553 & 1 & 14 & 5.3 \\
\hline
\end{tabular}

Estrutura etária semelhante foi encontrada por Agostinho et al. (2005), no reservatório de Itaipu, no ano de 2004. Estes pesquisadores verificaram que a faixa etária dominante era a de 40 a 50 anos e que apenas $3 \%$ dos pescadores tinham idade inferior a 20 anos, concluindo que, em Itaipu, a tendência era que a classe de pescadores profissionais não venha a ser renovada.

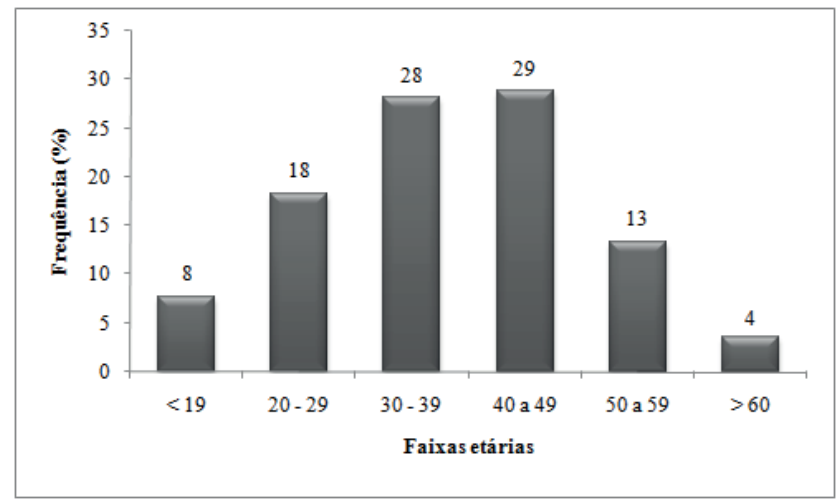

Figura 4. Histograma de frequência com as faixas etárias dos pescadores do reservatório da UHE Túcuruí, no ano de 2006 .

Ceregato e Petrere-Júnior (2002) encontraram, em estudo desenvolvido no Complexo de Urubupungá e a jusante no rio Paraná, que a maioria dos pescadores $(74,4 \%)$ tinham até 50 anos; acima dos 60 anos observavam apenas 7,9\% dos entrevistados. 
Segundo a Seteps (2003), a maior concentração dos pescadores situava-se nas faixas etárias entre 30 e 59 anos (55,4\%), sendo a faixa etária dominante a de 40 a 49 anos, com $31 \%$ dos pescadores, dados semelhantes aos encontrados no reservatório da UHE Tucuruí. No reservatório da UHE Tucuruí, a idade média dos pescadores entrevistados era de 37 anos, com mínimo e máximo de 14 e 64 anos.

No estudo realizado por Camargo (1998), ao longo do rio São Francisco, a idade média dos pescadores foi de 44,4 anos, com valor mínimo de 20 anos e máximo de 72 anos. Franca e Costa (1985) encontraram, para pescadores da zona centro da costa ocidental portuguesa, o valor médio de 40 anos. Já estudo realizado por Okada et al. (1997) mostrou que a idade média dos pescadores do reservatório de Segredo, no Estado do Paraná (rio Iguaçu), era de 37 anos, corroborando com a idade média encontrada para os pescadores do reservatório da UHE Tucuruí.

Segundo Ceregato e Petrere Júnior (2002), a pesca é uma atividade que não estabelece limite de idade para o seu exercício, podendo ser praticada durante todo o ano, com sazonalidade de produção. Esse argumento ajuda a compreender a permanência de pescadores na ativa, próximos a se aposentar ou aposentados, pois encontram na pesca fonte de renda complementar.

Quanto ao grau de escolaridade, o índice de analfabetismo entre os pescadores teve um percentual de $26,8 \%$, contrapondo-se aos que tinham $1^{\circ}$ grau incompleto, o qual teve uma representação de $71,8 \%$ do total, correspondendo, atualmente, ao ensino fundamental; e apenas $0,7 \%$ dos pescadores entrevistados chegaram a completar o ensino médio (Figura 5). Vale salientar que não houve pescadores que tivessem o $2^{\circ}$ grau incompleto.

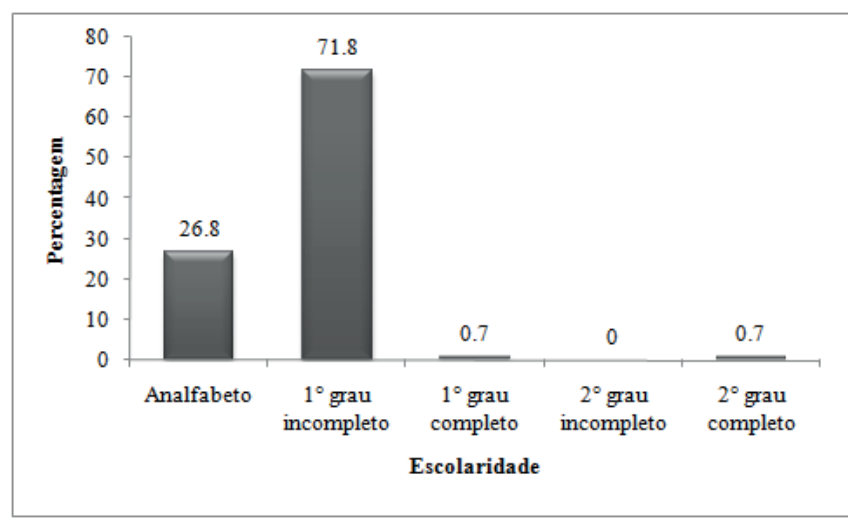

Figura 5. Escolaridade dos pescadores entrevistados do reservatório da UHE Tucuruí, no ano de 2006.
Estes dados são semelhantes aos encontrados para todos os pescadores do Estado do Pará, pela Seteps (2003). Seus dados revelaram que 20,5\% dos pescadores artesanais do Pará eram analfabetos, 78,9\% apresentavam escolaridade no nível de primeiro grau incompleto e apenas $0,5 \%$ chegaram ao segundo grau.

Silva, Oliveira e Nunes (2007) identificaram, em estudo realizado em Conceição do Araguaia (PA), que um dos grandes problemas sociais encontrados neste município era o alto índice de analfabetismo existente entre os integrantes desta profissão: $27 \%$ eram analfabetos e $57 \%$ tinham o fundamental incompleto. Assim como no trabalho realizado no reservatório da UHE de Tùcuruí, a maior parte dos entrevistados possuía apenas o $1^{\circ}$ grau incompleto, ou seja, frequentou somente até as primeiras séries da educação básica. Os pescadores relataram que em comunidades distantes das sedes municipais era oferecido, no máximo, até a $4^{\mathrm{a}}$ série do ensino fundamental, explicando o alto índice encontrado de fundamental incompleto.

O tempo na atividade pesqueira dividiu os pescadores em dois grupos: um grupo que atuava na pesca há mais de 20 anos, com $28 \%(\mathrm{n}=39)$, e outro com menos de 19 anos na profissão, com $72 \%(\mathrm{n}=103)$ dos entrevistados. Os pescadores com até 4 anos de atividade (12\%) e de 5 a 9 anos de atividade $(25,4 \%)$ representam, juntos, mais de $37 \%$ dos pescadores do reservatório; estes dados indicam que ainda há pessoas ingressando na pesca e que a atividade pesqueira no reservatório ainda é sustentável.

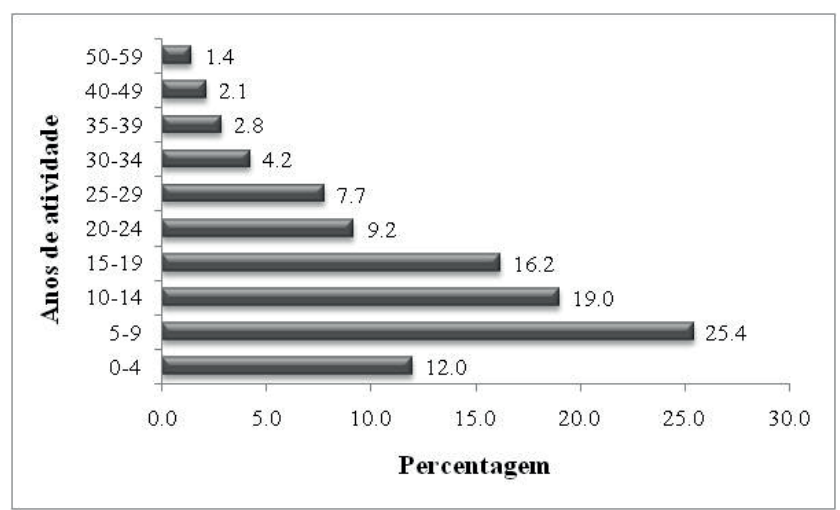

Figura 6. Anos de atividade na pesca dos pescadores entrevistados do reservatório da UHE de Tucuruí, no ano de 2006.

Na divisão dos dois grupos foi considerado o período de existência do reservatório (1985, ano de 
criação) e o ano da coleta de dados (2006), chegando aos 21 anos (Figura 6). Minte-Vera (1997) encontrou, no reservatório de Billings (São Paulo), que $66 \%$ dos pescadores nunca haviam pescado em outro local e os que já pescaram em outros lugares mencionavam principalmente outros reservatórios.

Dos 142 pescadores, $41 \%$ nunca haviam exercido outra atividade além da pesca, e $33 \%$ vinham da agricultura. Devido à grande quantidade de carpintarias na região, registrou-se 5\% de carpinteiros. As atividades anteriores, agrupadas na categoria outras* (18\%), incluem marreteiros/atravessadores, oleiros, açougueiros, ajudantes de siderúrgica, piloteiros, operadores de motosserra, estivadores, garimpeiros, pedreiros, pintores, cabeleireiros, soldadores, professores, frentistas e aposentados (Figura 7).

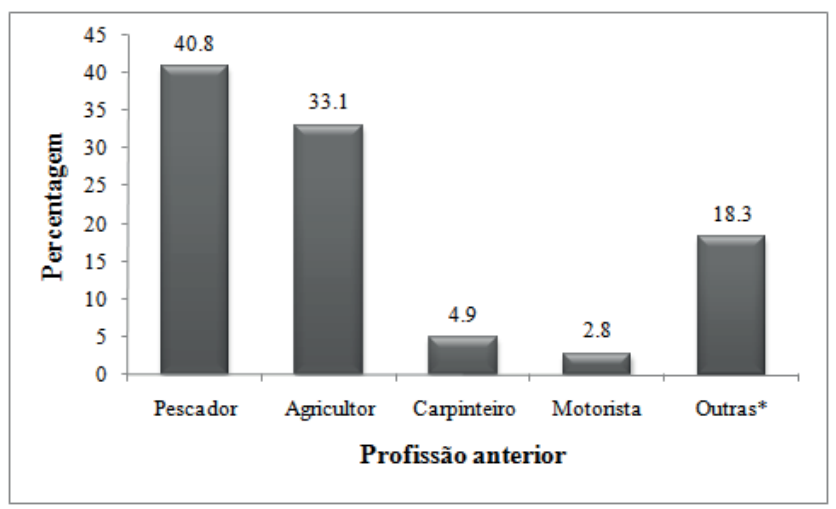

Figura 7. Profissão anterior exercida pelos pescadores entrevistados do reservatório da UHE de Tucuruí, no ano de 2006.

Em entrevistas com pescadores do reservatório de Itaipu no ano de 2004, Agostinho et al. (2005) encontraram que $28,3 \%$ dos pescadores, antes mesmo de ingressarem na pesca em Itaipu, já trabalhavam como pescadores e que $30,2 \%$ tinham vindo da agricultura.

A importância da pesca dentro do reservatório de Tucuruí é inquestionável, seja do ponto de vista econômico ou social. Todavia, tem ocorrido, nos últimos anos, uma redução das espécies ictíicas no lago, sendo este fato constatado pelos próprios pescadores e por pesquisadores como Ferreira e Zuanon (2000), que relatam a redução dos desembarques de tucunarés.

Quando questionados a respeito da redução das espécies no reservatório, os pescadores afirmaram que não só os tucunarés estavam escasseando, mas também a pescada-branca, o mapará, o curi- matã e o jaraqui. Para a maior parte dos pescadores (88\%), a quantidade de peixes existentes no reservatório já não era a mesma dos primeiros anos após a construção da barragem e isso não se aplicava a uma única espécie. A escassez era percebida como afetando as várias espécies, o que suscitava preocupação entre os pescadores, pois eles tinham de se deslocar para lugares cada vez mais distantes em busca do pescado, aumentando o tempo de pesca e, consequentemente, os custos das viagens, que podiam não ser cobertos no momento da comercialização. Muitos pescadores afirmavam que, por vezes, a pescaria mal cobria os custos da viagem, não sendo raros os casos de prejuízo.

Os pescadores apontaram vários fatores responsáveis pela redução do pescado. São eles: o aumento populacional, o aumento do número de pescadores, a destruição dos habitats naturais, o uso de redes malhadeiras com malha pequena, o uso de arpão por mergulhadores, o desrespeito aos períodos de defeso decretados na região, a liberação da pesca com anzol durante o defeso e, por fim, a falta de fiscalização por parte dos órgãos competentes.

$\mathrm{O}$ aumento do esforço de pesca, em função do elevado número de pescadores atuantes na região, foi apontado em $50 \%$ das entrevistas, sendo considerado como o principal responsável pela redução da produção no reservatório. Eles explicaram que o número de pessoas atuando na pesca era demasiado e os recursos já não eram suficientes para todos.

Outro problema identificado foi o uso de malhadeiras, apontado por $10 \%$ dos pescadores, principalmente quando elas são utilizadas ilegalmente, com malhas pequenas (tamanho inferior a $70 \mathrm{~mm}$ entre nós opostos), ou durante o defeso. Ademais, a utilização de redes para a captura de espécies de pequeno porte, como a jatuarana-escama-grossa, Hemiodus unimaculatus (BLOCH, 1794), com malha de $40 \mathrm{~mm}$, acaba se tornando um sério problema no reservatório. Ela atua sobre o estoque adulto dessa espécie, mas, devido ao reduzido tamanho da malha, captura jovens de outras espécies de maior porte, como a pescada-branca e os tucunarés.

De fato, a rede de emalhar é uma arte de pesca bastante seletiva, uma vez que são capturados apenas peixes de um determinado intervalo de comprimento (FONTELES-FILHO, 1989). Quando possui malha pequena, gera impactos indesejados sobre a fauna acompanhante e as respectivas comunidades biológicas, contribuindo para uma situação de insustentabilidade ecológica (CASTELLO, 2004). 
A maioria dos pescadores (75\%) utilizava malhas superiores a $80 \mathrm{~mm}$ (entre nós opostos). Mas eles creditavam à falta de fiscalização por parte do órgão competente na região, o Instituto Brasileiro do Meio Ambiente e dos Recursos Naturais Renováveis (Ibama), o frequente uso de redes impróprias.

Outros problemas mencionados foram a desobediência ao período de defeso e, novamente, a falta de fiscalização pelos órgãos responsáveis. O período de defeso é determinado pela Instrução Normativa $\mathrm{N}^{\circ} 46$, de 27 de outubro de 2005 , que define o defeso para as bacias hidrográficas dos rios Tocantins e Gurupí de $1^{\circ}$ de novembro a 28 de fevereiro de cada ano (MINISTÉRIO..., 2005). Essa instrução determina que, durante esse período, seja permitida apenas a pesca com o uso de molinete, caniço simples, linha-de-mão ou espinhel, proibindo-se o uso de malhadeiras. No entanto, pescadores aproveitavam essa liberação da pesca com determinados apetrechos para continuar utilizando a malhadeira nas pescarias, com a justificativa de que iriam utilizar artes de anzol, levando as redes escondidas na embarcação.

Agostinho (1997) explica que a depleção dos recursos pesqueiros em reservatórios não é surpresa, haja vista que o principal problema é a pesca desordenada que se instala nesses ambientes logo após a formação do reservatório, sem nenhum planejamento. No início, a alta produtividade, devido ao aporte de nutrientes das áreas alagadas, atrai um grande número de indivíduos à atividade. Quando a fase heterotrófica (decomposição da matéria orgânica alagada) termina, a produtividade diminui, inviabilizando a manutenção do esforço de pesca inicial. A persistência do mesmo esforço diminui os estoques, fazendo com que o rendimento caia ainda mais.

Por outro lado, tratando-se de uma área nova de pesca, com muitos pescadores recém-chegados, é comum a falta de organização, ou de instituições que conduzam à regulação da atividade. Nesse contexto, gera-se uma situação típica de livre acesso aos recursos, potencialmente geradora da "tragédia dos recursos comuns", no sentido discutido por Hardin (1968) e Ostrom (1990). A gestão da atividade, portanto, torna-se particularmente necessária a partir das mudanças sociais e ambientais que se manifestam com o passar dos anos, no reservatório.

O controle da pesca, realizado com o objetivo de proteger as formas jovens, áreas de reprodução e períodos de desova dos estoques pesqueiros, tem se mostrado pouco eficiente, tanto pela escassez de informações acerca do objeto do controle, como pelas limitações de recursos financeiros e humanos relacionados a esta atividade. A ausência de um monitoramento permanente da exploração e do recurso, exigido pela dinâmica do sistema, e a falta de uma definição clara do que se pretende proteger são outros aspectos que afetam a eficiência do controle (AGOSTINHO, 1992).

Alguns problemas de conflito foram identificados entre os pescadores de anzol e os pescadores de malhadeira, com relação ao uso do espaço. Os pescadores de anzol afirmavam que o excesso de "redes" no lago espantava os peixes das áreas de pesca, sendo mais difícil encontrá-los, além do uso ilegal do arpão na captura de mergulho, que é considerada uma prática altamente predatória. Segundo o relato dos pescadores, a pesca com anzol tinha um rendimento de $200 \mathrm{~kg} /$ pescador/viagem. $\mathrm{Na}$ época da pesquisa de campo, esse valor baixara para $20 \mathrm{~kg} /$ pescador/viagem.

De um modo geral, nas entrevistas, os pescadores partilhavam uma opinião muito crítica a respeito dos problemas existentes no reservatório, sugerindo alternativas para sua solução, como a criação de políticas ambientais e de conscientização do pescador artesanal. Peres, Klippel e Vianna (2007) afirmam que pescadores profissionais artesanais, principalmente aqueles que têm a pesca como única atividade, são os parceiros naturais de qualquer processo de conservação ambiental e, também, os mais comprometidos com a causa. Esse argumento dos autores corrobora as perspectivas e propostas formuladas pelos pescadores em Tùcuruí para uma melhor gestão da atividade.

A proibição da pesca foi sugerida por $50 \%$ dos entrevistados. Nessa hipótese, a atividade pesqueira seria interrompida no reservatório, inclusive a pesca com anzol, com o objetivo de tentar recuperar os estoques pesqueiros. Nesse período, os pescadores receberiam um seguro pelo tempo em que a pesca ficasse impedida. Contudo, Alves e Barthem (2008) identificaram um grande entrave nessa alternativa, que é o elevado contingente de trabalhadores atuantes na pesca, o que consequentemente geraria um custo enorme para o governo, por meio do pagamento dos benefícios. Deve-se citar, também, os altos custos de monitoramento, considerando que os valores dos benefícios não cobrem as necessidades monetárias das famílias por longos períodos, não se configurando, assim, incentivos suficientes para muitos desses trabalhadores interromperem a pesca por todo o tempo que fosse acordado. 
Também foram sugeridos incentivos a outras atividades econômicas, como a agricultura, a fruticultura e a piscicultura. A prática da aquicultura em reservatórios tem sido vista como uma alternativa para reduzir a pressão sobre os estoques naturais e para gerar novas fontes de renda para os pescadores artesanais, necessárias diante da diminuição dos estoques (AGOSTINHO; GOMES, 2005). Entretanto, essa prática pode ser prejudicial se utilizadas espécies exóticas à bacia.

Em reservatórios brasileiros, com a constante diminuição dos recursos pesqueiros, o vertiginoso aumento da demanda e a diversificação dos usuários, a criação de formas de controle assume um aspecto crítico, devendo anteceder ou ser concomitante a programas de educação ambiental (AGOSTINHO; GOMES; PELICICE, 2007).

Entretanto, quando se analisa a sustentabilidade do setor pesqueiro, é importante também considerar que a redução dos estoques não é consequência exclusiva da pesca, mas também de ações antrópicas no ambiente de entorno. Destaca-se a derrubada de matas ciliares, a destruição de nascentes, o assoreamento, a poluição e o represamento dos rios (SANTOS; SANTOS, 2005), problemas que também foram apontados pelos pescadores do reservatório da UHE Tùcuruí.

\section{Conclusões}

A maior parte dos pescadores é paraense (55\%), mas com volumosa presença de migrantes. A Região Nordeste é a principal região de origem dos migrantes, com destaque para o Estado do Maranhão.

Os homens predominaram na amostra, $68 \%$ de entrevistados, para $32 \%$ de entrevistadas. A grande maioria vive maritalmente (74\%), com idade média de 37 anos e, em média, possuem 3 a 4 filhos/pescador. O nível de escolaridade é muito baixo e cerca de $41 \%$ nunca havia exercido outra atividade além da pesca.

Os pescadores acreditam que a produção $(\mathrm{kg})$ de pescado no reservatório está reduzindo e que as causas são: desrespeito ao período de defeso, liberação da pesca com anzol durante o defeso, falta de fiscalização por parte dos órgãos competentes, destruição dos habitats naturais, aumento populacional, uso de malhadeiras de malha pequena e grande quantidade de pescadores.

\section{Referências}

AGOSTINHO, A.A. Manejo de recursos pesqueiros em reservatórios. In: AGOSTINHO, A.A.; BENEDITO-CECILIO, E. (Eds.). Situação atual e perspectivas da ictiologia no Brasil. Maringá: Editora da UEM, 1992. p.106-121.

. A exploração dos recursos aquáticos continentais e a biodiversidade. Boletim da Sociedade Brasileira de Ictiologia, Maringá, n.49, p.6, 1997.

AGOSTINHO, A.A.; GOMES, L.C. O manejo da pesca em reservatórios da bacia do alto rio Paraná: avaliação e perspectivas. In: NOGUEIRA M.G.; HENRY, R.; JORCIN A. (Eds.). Ecologia de reservatórios: impactos potenciais, ações de manejo e sistemas em cascata. São Carlos: Rima, 2005. p.23-55.

AGOSTINHO, A.A.; GOMES, L.C.; PELICICE, F.M. Ecologia e manejo de recursos pesqueiros em reservatórios do Brasil. Maringá: Eduem, 2007. v.1, $501 \mathrm{p}$.

AGOSTINHO, A.A.; OKADA, E.K.; GOMES, L.C.; AMBRÓSIO, A.M.; SUZUKI, H.I. Reservatório de Itaipu: estatística de rendimento pesqueiro. Relatório Anual (2004). Maringá, 2005. v.1, 307p.

ALMEIDA, O.; LORENZEN, K.; MCGRATH, D.; AMARAL, L. O setor pesqueiro na economia regional. In: ALMEIDA, O. (Ed.). Manejo de pesca na Amazônia brasileira. São Paulo: Peirópolis, 2006. p.25-36.

ALVES, M.C.B.; BARTHEM, R.B. A pesca comercial dos "tucunarés" Cichla spp. (Perciformes, Cichlidae) no reservatório da UHE-Tucuruí, rio Tocantins, PA. Boletim do Instituto de Pesca, São Paulo, v.34, n.4, p.553-561, 2008.

ANDERSON, D.R.; SWEENEY, D.J.; WILLIAMS, T.A. Estatística aplicada à administração e economia. São Paulo: Pioneira, 2002. 642p.

BRASIL, M.; TEIXEIRA, P. A demografia das comunidades rurais estudadas pelo projeto PIATAM. In: TEIXEIRA, P.; BRASIL, M.; RIVA, A. (Eds.). Produzir e viver na Amazônia rural: estudo sócio demográfico de comunidades do médio Solimões. Manaus: Edua, 2007. p.67-105.

CAMARGO, S.A.F. Sociobiologia da gestão participativa dos pescadores comerciais do rio São Francisco, MG, Brasil. 1998. 122f. Dissertação (Mestrado em Conservação e Manejo de Recursos, Área de Concentração: Gestão Integrada de Recursos) 
- Centro de Estudos Ambientais, Universidade Estadual Paulista, Rio Claro, 1998.

CAMARGO, S.A.F.; PETRERE-JÚNIOR, M. Análise de risco aplicada ao manejo precaucionário das pescarias artesanais na região do reservatório da UHE - Tucuruí (Pará, Brasil). Acta Amazonica, Manaus, v.34, n.3, p.473-485, 2004.

CASTELLO, J.P. Manejo da pesca e a interdisciplinaridade. Desenvolvimento e Meio Ambiente, Curitiba, n.10, p.163-168, 2004.

CEREGATO, S.A.; PETRERE-JÚNIOR, M. Aspectos sócio-econômicos das pescarias artesanais realizadas no complexo Urubupungá e a sua jusante no rio Paraná. Holos Environment, Rio Claro, v.2, n.1, p.1-24, 2002.

COMISSÃO MUNDIAL DE BARRAGENS. Estudo de caso da Usina Hidrelétrica de Tucuruí (Brasil): relatório final da fase de escopo. Rio de Janeiro. 1999. 80p.

COSTA, F.J.C.B. Pesca e aqüicultura: últimos peixes ou milagre da multiplicação. In: ENCONTRO DE ZOOLOGIA DO NORDESTE, 14, 2003, Maceió. Anais... Maceió: Sociedade Nordestina de Zoologia, 2003. p.95-96.

FERREIRA, E.J.G.; ZUANON, J.A.S. Ictiofauna da UHE Tucuruí, rio Tocantins. In: Usina Hidrelétrica de Tucuruí (Brasil) - Relatório Final. WCD Case Study, 2000. p.106-121.

FONTELES-FILHO, A.A. Recursos pesqueiros: biologia e dinâmica populacional. Fortaleza: Imprensa Oficial do Ceará, 1989. 296p.

FRANCA, M.P.L.; COSTA, F.C. Pesca artesanal na zona centro da costa ocidental portuguesa. Boletim do Instituto Nacional de Investigação das Pescas, v.3, p.8-10, 1985.

GOULDING, M. Amazonian fisheries. In: MORAN, E.F. (Ed.) The dilemma of Amazonian development. Colorado: Westview Press, 1983. p.189-210.

HARDIN, G. The tragedy of the commons. Science. v.162, n.3859, p.1243-1248, 1968.

INSTITUTO BRASILEIRO DE GEOGRAFIA E ESTATÍSTICA. Síntese de indicadores sociais: uma análise das condições de vida da população brasileira. Rio de Janeiro, 2008. 280p.

JURAS, A.A.; CINTRA, I.H.A.; LUDOVINO, R.M.R. A pesca na área de influência da Usina Hi- drelétrica de Tùcuruí, estado do Pará. Boletim Técnico Científico do Cepnor, Belém, v.4, n.1, p.77-88, 2004.

MANESCHY, M.C. A mulher está se afastando da pesca? Continuidade e mudança no papel da mulher na manutenção doméstica entre famílias de pescadores no litoral do Pará. Boletim do Museu Paraense Emilio Goeldi. Antropologia, Belém, v.11, n.2, p.145-166, 1995.

MINISTÉRIO DO MEIO AMBIENTE E DOS RECURSOS NATURAIS NÃO-RENOVÁVEIS. Instrução Normativa 46, de 27 de outubro de 2005. Diário Oficial da União. Brasília, 2005.

MINTE-VERA, C.V. A pesca artesanal no reservatório Billings (São Paulo). 1997. 86f. Dissertação (Mestrado em Ciências Biológicas, Área de Ecologia) - Instituto de Biologia da Universidade Estadual de Campinas, Campinas, 1997.

OKADA, E.K.; GREGORIS, J.; AGOSTINHO, A.A.; GOMES, L.C. Diagnóstico da pesca profissional em dois reservatórios do rio Iguaçu. In: AGOSTINHO, A. A.; GOMES, L. C. Reservatório de Segredo: bases ecológicas para o manejo. Maringá: UEM, 1997, p.293-318.

OSTROM, E. Governing the commons: the evolution of institutions for collective action. Cambridge: Cambridge University Press, 1990. 280p.

PERES, M.B.; KLIPPEL, S.E.; VIANNA, M.A.C. Áreas de exclusão de pesca propostas no processo de gestão participativa da pesca artesanal no litoral norte do Rio Grande do Sul: um relato de experiência. In: Áreas aquáticas protegidas como instrumento de gestão pesqueira. Brasília: MMA, 2007. v.4. p.131-144.

SANTOS, G.M.; SANTOS, A.C.M. Sustentabilidade da pesca na Amazônia. Acta Amazônica, Manaus, v.19, n.54, p.165-182, 2005.

SECRETARIA EXECUTIVA DE TRABALHO E PROMOÇÃO SOCIAL. A pesca artesanal do Estado do Pará: perfil sócio-econômico e organização dos pescadores filiados às Colônias. Belém: Seteps/ Sine-PA, 2003. 154p.

SILVA, M.C.; OLIVEIRA, A.S.; NUNES, G.Q. Caracterização socioeconômica da pesca artesanal no município de Conceição do Araguaia, Estado do Pará. Amazônia Ciência \& Desenvolvimento, Belém, v.2, n.4, p.37-51, 2007. 